\title{
Effect of Chronic Renal Failure and Hemodialysis on Carbohydrate Metabolism*
}

\author{
Constantine L. Hampers, $\dagger$ J. Stuart Soeldner, Peter B. Doak, $\ddagger$ and \\ JOH N P. MERRILL $\S$ \\ (From the Cardiorenal Laboratories and Clinical Research Center of the Peter Bent Brigham \\ Hospital, the Elliott P. Joslin Research Laboratory, the Diabetes Foundation, Inc., and \\ Harvard Medical School, Boston, Mass.)
}

It has been known for some time that patients with renal failure are unable to adequately handle a glucose load $(1,2)$. The mechanism of this carbohydrate intolerance is far from clear, and speculations as to its etiology have been made by various authors $(3,4)$. No uniform hypothesis is accepted; indeed, two articles appearing in the same issue of a journal arrived at totally different conclusions $(5,6)$.

With the advent of periodic hemodialysis, patients with chronic renal failure can be maintained in relatively good health over long periods of time (7), and the clinical syndrome of uremia can be evaluated under controlled conditions. If the abnormality of carbohydrate metabolism is truly a result of renal failure and not solely associated with nonspecific factors such as starvation, stress, or latent diabetes mellitus, an experiment controlling such variables might shed light on the metabolic defect or defects involved. Also the opportunity arises to study the effect of hemodialysis itself on carbohydrate metabolism. If glucose tolerance can be completely normalized by dialysis, this

* Submitted for publication April 25, 1966; accepted July 28, 1966.

Supported in part by grants IR-01-H-E-08260-01 and IR-01-AM09748-01 from the U. S. Public Health Service, Bethesda, Md., grant DA-49-193-MD-2497 from the U. S. Army Medical Research and Development Command, and by a grant from the John A. Hartford Foundation. These studies were carried out on the Clinical Research Center and were supported by grant 8 MD1-3104 from the National Institutes of Health.

An abstract of part of this work appeared in Clin. Res. 1965, 13, 307.

† Address requests for reprints to Dr. Constantine $\mathbf{L}$. Hampers, Peter Bent Brigham Hospital, 721 Huntington Ave., Boston, Mass. 02115.

$\ddagger$ Present address: Medical Unit, Public Hospital, Auckland, New Zealand.

§ Investigator, Howard Hughes Medical Institute. would be useful as an added parameter for determining the adequacy of long term dialysis in the individual patient.

\section{Methods}

The patients studied were those with chronic renal failure chosen from the renal service of the Peter Bent Brigham Hospital who would require hemodialysis for treatment within a few weeks. All had an abnormal intravenous glucose tolerance test (ivGTT) before hemodialysis ( $\mathrm{K}$ less than 1.0) (8). Four of the five patients selected had no family history of diabetes, and all patients were reasonably certain of the medical histories of their parents and at least three of their grandparents. The maternal grandmother of Patient 4 had maturityonset diabetes, being treated with diet and an oral hypoglycemic agent.

The patients were hospitalized on the Clinical Research Center of the Peter Bent Brigham Hospital for 6 or more days before testing, during which time daily dietary assessments were obtained on four of the five. In the fifth, the diet was estimated to be very similar to that of the other four patients. The diet consumed was greater than 1,800 calories, including more than $250 \mathrm{~g}$ of carbohydrate, and was followed throughout all periods. Testing of glucose tolerance did not begin until such a diet had been ingested for at least 5 days. Daily blood urea nitrogen, hematocrit, and serum electrolytes $\left(\mathrm{Na}^{+}\right.$, $\mathrm{K}^{+}, \mathrm{Cl}^{+}$, and $\mathrm{HCO}_{3}^{-}$) were obtained. Other laboratory determinations were performed as indicated. Blood samples for glucose measurement were collected in tubes containing sodium fluoride and potassium oxalate, and glucose was determined by the method of Somogyi (9) and Nelson (10). All of the patients were ambulatory and were allowed the freedom of the Clinical Research Center and hospital.

All tests were performed within a 50-hour segment at the end of each hemodialysis period. On day 1 of the segment, after an overnight fast, an ivGTT $(0.5 \mathrm{~g}$ of glucose per $\mathrm{kg}$ body weight injected over a 3-minute period) was performed, and samples of venous blood were collected at $0,3,6,10,20,30,40,50$, and 60 minutes. A specific disappearance rate constant for glucose (K) ${ }^{1}$

$$
1 \mathrm{~K}=\left(0.693 / \mathrm{t}_{3}\right) \times 100=\text { per cent per minute. }
$$


was calculated (8). In most instances throughout the test, duplicate blood samples were collected in clean tubes, allowed to clot for 2 hours at room temperature, and centrifuged; the serum was then removed, and samples were stored frozen until determination of serum immunoreactive insulin (IRI) by a double antibody technique $(11,12)$. In addition, the concentration of plasma free fatty acids (FFA) (13) was determined on samples drawn at $0,10,20,40$, and 60 minutes.

After an additional 5- to 7-hour fast, after the glucose tolerance test, an intravenous tolbutamide test (14) was performed ( $1 \mathrm{~g}$ of sodium tolbutamide given in $1 \mathrm{~min}$ ute), and venous blood samples were taken at 0,20 , and 30 minutes for glucose measurement.

On day 2, after an overnight fast, an intravenous insulin sensitivity test (15) was done ( $0.1 \mathrm{U}$ of crystalline insulin per $\mathrm{kg}$ body weight), and venous blood samples were taken at $0,20,30,40,50,60,90$, and 120 minutes for glucose determinations.

On day 3, again after an overnight fast, a glucagon test (1 $\mathrm{mg}$ of glucagon given rapidly intravenously) was carried out, and venous blood glucose was measured at 0,20 , and 30 minutes.

When a normal $\mathrm{K}$ value of greater than 1.0 (8) for the ivGTT was obtained, a steroid-primed ivGTT (16) was performed $(50 \mathrm{mg}$ of hydrocortisone was given orally 8 and again 2 hours before ivGTT).

The patients then underwent periods of hemodialysis with the twin coil kidney (5 hours per day) ranging from three to five dialyses per 7-day period. The dialysate composition was constant and included the following: $\mathrm{Na}^{+}=130 \mathrm{mEq}$ per $\mathrm{L}, \mathrm{K}^{+}=4 \mathrm{mEq}$ per $\mathrm{L}, \mathrm{Ca}^{++}$ $=3 \mathrm{mEq}$ per $\mathrm{L}, \mathrm{Mg}^{++}=2 \mathrm{mEq}$ per $\mathrm{L}, \mathrm{Cl}^{-}=104 \mathrm{mEq}$ per $\mathrm{L}$, acetate $=5 \mathrm{mEq}$ per $\mathrm{L}, \mathrm{HCO}_{3}{ }^{-}=30$ mmoles per $\mathrm{L}$, and glucose $=500 \mathrm{mg}$ per $100 \mathrm{mi}$. At the end of 1 to 2 weeks of dialysis, the ivGTT was repeated. If this test was not normal, another course of hemodialysis was instituted, and the ivGTT was repeated. If the ivGTT was then normal, the initial tests were repeated except that a hydrocortisone provocative ivGTT was substituted for the glucagon stimulation test.

After this "correction" period, hemodialysis was withheld for approximately 7 days while the diet was held constant. Then the ivGTT, insulin sensitivity test, and the intravenous tolbutamide test were repeated.

Whenever possible, another course of hemodialysis was instituted, and glucose tolerance was re-evaluated.
Two patients (No. 1 and 2) underwent hemodialysis with a high urea concentration in the dialysis bath in order to evaluate the effect of urea on carbohydrate metabolism. The concentration of urea used was determined by the level that the patient manifested during his initial testing. The urea was added to the dialysate at a time when the ivGTT was normal, and the patients underwent from three to six dialyses with urea in an 8-day period. The ivGTT was then repeated.

Four of the five patients investigated were followed according to the above protocol. One patient (No. 5), with poor veins, was evaluated only by the ivGTT. IRI and FFA were not determined with all ivGTT performed; however, these tests were obtained in each patient during at least one "normal" and "abnormal" ivGTT. In addition, four other patients, who had been maintained on biweekly hemodialysis for more than 4 months, were tested with an ivGTT.

The normal controls and the maturity-onset type diabetics were tested as outpatients at the Elliott P. Joslin Research Laboratory. All followed a $300-\mathrm{g}$ carbohydrate diet for 3 days before the test. The diabetic patients were asymptomatic, their glucose intolerance having been documented on multiple occasions.

\section{Results}

Table I shows clinical data on the uremic patients studied. Four were male; all of the five were less than $100 \%$ of ideal weight. Their ages ranged from 27 to 45 years.

Table II contains the composite data for the group. The ivGTT, which had been abnormal initially, reverted to normal in all patients within 16 days. The number of dialyses performed during the initial correction period ranged from 5 to 13. It can be noted that the blood urea nitrogen and serum creatinine were only rough indicators of the normalcy of the ivGTT. None of the patients was severely acidotic (as judged by serum $\mathrm{HCO}_{8}{ }^{-}$concentration) at any time during the study, and bicarbonate levels ranged from 20 to 26 mmoles per $\mathrm{L}$ with a mean of 23 mmoles per $\mathrm{L}$. Serum potassium was also not markedly de-

TABLE I

Clinical data on patients studied

\begin{tabular}{|c|c|c|c|c|c|c|}
\hline Patient & Sex & Age & Underlying disease & $\begin{array}{c}\text { Average } \\
\text { wt }\end{array}$ & Height & $\begin{array}{c}\% \text { Ideal } \\
\text { wt* }\end{array}$ \\
\hline & & years & & $k g$ & & \\
\hline $\begin{array}{l}1 \\
2 \\
3 \\
4 \\
5\end{array}$ & $\begin{array}{l}\text { Male } \\
\text { Male } \\
\text { Male } \\
\text { Male } \\
\text { Female }\end{array}$ & $\begin{array}{l}27 \\
28 \\
45 \\
35 \\
35\end{array}$ & $\begin{array}{l}\text { Chronic glomerulonephritis } \\
\text { Chronic glomerulonephritis } \\
\text { Chronic pyelonephritis } \\
\text { Chronic glomerulonephritis } \\
\text { Chronic pyelonephritis }\end{array}$ & $\begin{array}{l}63 \\
59 \\
62 \\
66 \\
43\end{array}$ & $\begin{array}{l}5^{\prime} 10^{\prime \prime} \\
5^{\prime} 11^{\prime \prime} \\
5^{\prime} 8^{\prime \prime} \\
5^{\prime} 11^{\prime \prime} \\
5^{\prime} 2^{\prime \prime}\end{array}$ & $\begin{array}{l}88 \\
79 \\
85 \\
85 \\
74\end{array}$ \\
\hline
\end{tabular}

* Metropolitan Life Insurance tables. 
TABLE II

Composite results of carbohydrate tolerance*

\begin{tabular}{|c|c|c|c|c|c|c|c|c|c|c|}
\hline \multirow[b]{2}{*}{ Patient } & \multirow[b]{2}{*}{ Period } & \multirow[b]{2}{*}{ BUN } & \multirow{2}{*}{$\begin{array}{l}\text { Creat- } \\
\text { inine }\end{array}$} & \multirow{2}{*}{$\begin{array}{l}\text { Serum } \\
\text { potas- } \\
\text { sium }\end{array}$} & \multirow{2}{*}{$\begin{array}{l}\text { Serum } \\
\mathrm{HCO}-\end{array}$} & \multirow{2}{*}{$\underset{(\mathrm{K})}{\text { ivGT }}$} & \multicolumn{2}{|c|}{ iv tolbutamide } & \multirow[b]{2}{*}{ IST } & \multirow{2}{*}{$\begin{array}{l}\text { No. dialyses } \\
\text { per total } \\
\text { days }\end{array}$} \\
\hline & & & & & & & $20 \mathrm{~min}$ & $30 \mathrm{~min}$ & & \\
\hline & & $m g / 100 m l$ & $m g / 100 m l$ & $m E q / L$ & mmoles $/ L$ & & \multicolumn{2}{|c|}{$\%$ of $F B S$} & $\%$ of $F B S$ & \\
\hline 1 & $\begin{array}{l}1 \\
2 \\
3 \dagger \\
4 \\
5\end{array}$ & $\begin{array}{r}174 \\
36 \\
30 \\
33 \\
33 \\
31\end{array}$ & $\begin{array}{c}20 \\
5.3 \\
4.9 \\
6.4 \\
5.4 \\
5.0\end{array}$ & $\begin{array}{l}4.6 \\
5.3 \\
4.0 \\
5.2 \\
5.3 \\
4.4\end{array}$ & $\begin{array}{l}22 \\
21 \\
22 \\
21 \\
24 \\
25\end{array}$ & $\begin{array}{l}0.8 \\
0.6 \\
1.0 \\
1.7 \\
1.9 \\
1.2\end{array}$ & $\begin{array}{c}100 \\
95 \\
84 \\
77 \\
75 \\
\text { ND }\end{array}$ & $\begin{array}{r}86 \\
84 \\
74 \\
68 \\
63 \\
\text { ND }\end{array}$ & $\begin{array}{c}52 \\
51 \\
50 \\
25 \\
24 \\
\text { ND }\end{array}$ & $\begin{array}{l}0 \\
5 / 7 \\
5 / 7 \\
3 / 4 \\
5 / 7 \\
1 / 1\end{array}$ \\
\hline \multicolumn{11}{|c|}{ (Hydrocortisone) } \\
\hline & $\begin{array}{l}6 \ddagger \\
7 \\
8 \\
9\end{array}$ & $\begin{array}{r}166 \\
100 \\
24 \\
32\end{array}$ & $\begin{array}{r}5.6 \\
15.5 \\
8.2 \\
5.2\end{array}$ & $\begin{array}{l}4.0 \\
5.5 \\
4.8 \\
4.3\end{array}$ & $\begin{array}{l}24 \\
21 \\
25 \\
24\end{array}$ & $\begin{array}{l}1.7 \\
0.9 \\
1.0 \\
2.0\end{array}$ & $\begin{array}{l}68 \\
87 \\
85 \\
68\end{array}$ & $\begin{array}{l}60 \\
77 \\
73 \\
61\end{array}$ & $\begin{array}{l}23 \\
48 \\
24 \\
22\end{array}$ & $\begin{array}{l}6 / 8 \\
1 / 7 \\
2 / 7 \\
2 / 7\end{array}$ \\
\hline 2 & $\begin{array}{l}1 \\
2 \\
3\end{array}$ & $\begin{array}{r}112 \\
48 \\
28 \\
30\end{array}$ & $\begin{array}{r}14.2 \\
4.7 \\
7.0 \\
6.0\end{array}$ & $\begin{array}{l}5.4 \\
4.8 \\
4.4 \\
4.0\end{array}$ & $\begin{array}{l}22 \\
21 \\
24 \\
23\end{array}$ & $\begin{array}{l}0.6 \\
1.5 \\
1.4 \\
1.3\end{array}$ & $\begin{array}{r}84 \\
74 \\
71 \\
N D\end{array}$ & $\begin{array}{r}83 \\
72 \\
70 \\
\text { ND }\end{array}$ & $\begin{array}{r}58 \\
32 \\
28 \\
\text { ND }\end{array}$ & $\begin{array}{l}0 \\
5 / 14 \\
5 / 14 \\
1 / 1\end{array}$ \\
\hline \multicolumn{11}{|c|}{ (Hydrocortisone) } \\
\hline & $\begin{array}{l}4 \ddagger \\
5 \dagger \\
6 \\
7\end{array}$ & $\begin{array}{r}112 \\
106 \\
40 \\
43\end{array}$ & $\begin{array}{r}8.0 \\
18.7 \\
7.2 \\
9.2\end{array}$ & $\begin{array}{l}4.6 \\
3.6 \\
4.0 \\
4.1\end{array}$ & $\begin{array}{l}24 \\
20 \\
22 \\
23\end{array}$ & $\begin{array}{l}2.0 \\
0.5 \\
1.0 \\
1.4\end{array}$ & $\begin{array}{c}83 \\
84 \\
\text { ND } \\
72\end{array}$ & $\begin{array}{c}63 \\
84 \\
\text { ND } \\
68\end{array}$ & $\begin{array}{c}30 \\
44 \\
N D \\
30\end{array}$ & $\begin{array}{l}3 / 8 \\
1 / 8 \\
6 / 8 \\
6 / 14\end{array}$ \\
\hline 3 & $\frac{1}{2} \dagger$ & $\begin{array}{l}54 \\
65\end{array}$ & $\begin{array}{r}10.4 \\
7.8\end{array}$ & $\begin{array}{l}4.9 \\
5.3\end{array}$ & $\begin{array}{l}24 \\
23\end{array}$ & $\begin{array}{l}0.7 \\
1.5\end{array}$ & $\begin{array}{c}84 \\
\text { ND }\end{array}$ & $\begin{array}{c}77 \\
\text { ND }\end{array}$ & $\begin{array}{c}38 \\
\text { ND }\end{array}$ & $\begin{array}{l}1 / 2 \\
8 / 16\end{array}$ \\
\hline \multicolumn{11}{|c|}{ 10-week bout of hepatitis after bilateral nephrectomy } \\
\hline & $\begin{array}{l}3 \\
4\end{array}$ & $\begin{array}{l}35 \\
43 \\
26\end{array}$ & $\begin{array}{l}6.8 \\
8.0 \\
7.5\end{array}$ & $\begin{array}{l}5.0 \\
5.2 \\
4.8\end{array}$ & $\begin{array}{l}22 \\
22 \\
25\end{array}$ & $\begin{array}{l}0.8 \\
1.9 \\
1.2\end{array}$ & $\begin{array}{c}\text { ND } \\
74 \\
\text { ND }\end{array}$ & $\begin{array}{c}\text { ND } \\
64 \\
\text { ND }\end{array}$ & $\begin{array}{l}\text { ND } \\
20 \\
\text { ND }\end{array}$ & $\begin{array}{l}5 / 7 \\
4 / 8 \\
1 / 1\end{array}$ \\
\hline \multicolumn{11}{|c|}{ (Hydrocortisone) } \\
\hline & $\begin{array}{l}5 \\
6\end{array}$ & $\begin{array}{l}85 \\
38\end{array}$ & $\begin{array}{l}9.6 \\
5.8\end{array}$ & $\begin{array}{l}4.0 \\
4.6\end{array}$ & $\begin{array}{l}22 \\
24\end{array}$ & $\begin{array}{l}1.0 \\
1.6\end{array}$ & $\begin{array}{l}80 \\
72\end{array}$ & $\begin{array}{l}74 \\
61\end{array}$ & $\begin{array}{l}26 \\
18\end{array}$ & $\begin{array}{l}1 / 6 \\
4 / 12\end{array}$ \\
\hline 4 & $\begin{array}{l}1 \dagger \\
2 \\
3\end{array}$ & $\begin{array}{r}110 \\
69 \\
38 \\
38\end{array}$ & $\begin{array}{r}16.3 \\
4.8 \\
6.0 \\
5.8\end{array}$ & $\begin{array}{l}5.8 \\
5.4 \\
4.6 \\
4.8\end{array}$ & $\begin{array}{l}21 \\
22 \\
26 \\
24\end{array}$ & $\begin{array}{l}0.6 \\
1.1 \\
1.8 \\
0.7\end{array}$ & $\begin{array}{l}88 \\
\text { ND } \\
72 \\
\text { ND }\end{array}$ & $\begin{array}{c}68 \\
\text { ND } \\
63 \\
\text { ND }\end{array}$ & $\begin{array}{c}32 \\
\text { ND } \\
18 \\
\text { ND }\end{array}$ & $\begin{array}{l}0 \\
3 / 8 \\
3 / 8 \\
1 / 1\end{array}$ \\
\hline \multicolumn{11}{|c|}{ (Hydrocortisone) } \\
\hline & 4 & 114 & 10.8 & 4.4 & 20 & 0.8 & 83 & 78 & 38 & $0 / 5$ \\
\hline 5 & $\begin{array}{l}1 \\
2 \\
3 \\
4 \\
5\end{array}$ & $\begin{array}{r}126 \\
33 \\
38 \\
26 \\
22\end{array}$ & $\begin{array}{l}9.2 \\
5.8 \\
8.6 \\
7.4 \\
6.0\end{array}$ & $\begin{array}{l}5.2 \\
4.4 \\
5.0 \\
5.0 \\
4.5\end{array}$ & $\begin{array}{l}22 \\
24 \\
23 \\
21 \\
23\end{array}$ & $\begin{array}{l}0.9 \\
1.3 \\
1.0 \\
0.9 \\
1.3\end{array}$ & $\begin{array}{l}\text { ND } \\
\text { ND } \\
\text { ND } \\
\text { ND } \\
\text { ND }\end{array}$ & $\begin{array}{l}\text { ND } \\
\text { ND } \\
\text { ND } \\
\text { ND } \\
\text { ND }\end{array}$ & $\begin{array}{l}\text { ND } \\
\text { ND } \\
\text { ND } \\
\text { ND } \\
\text { ND }\end{array}$ & $\begin{array}{l}0 \\
8 / 14 \\
4 / 18 \\
3 / 7 \\
6 / 12\end{array}$ \\
\hline
\end{tabular}

* All tests were performed at the end of the period noted under "No. dialyses per total days." They were performed in from 1 to 50 hours (see Methods), and the time involved in testing is not included in the time of the next period. The time taken for testing depended on the number of tests performed. The order of testing and the time involved were as follows: iv glucose tolerance test (ivGTT) ( 1 hour) + iv tolbutamide ( 24 hours) + insulin sensitivity test (IST) (26 hours) + glucagon stimulation test (50 hours). The final dialysis was instituted on the last day of each period (the period ending the following morning), and the remaining dialyses were distributed as evenly as possible throughout the entire period. The blood biochemical data were obtained at the time of ivGTT. BUN = blood urea nitrogen; FBS $=$ fasting blood sugar $; \mathrm{K}=$ disappearance rate constant for glucose $\mathrm{ND}=$ not done.

† Glucagon test ( $\%$ of FBS): Patient $1=175$, Patient $2=170$, Patient $3=154$, and Patient $4=182$. $100 \mathrm{ml}$

$\ddagger$ Urea added to dialysis bath throughout entire period: Patient $1=170 \mathrm{mg}$ per $100 \mathrm{ml}$ and Patient $2=120 \mathrm{mg}$ per 


\section{I.V. TOLBUTAMIDE TEST}

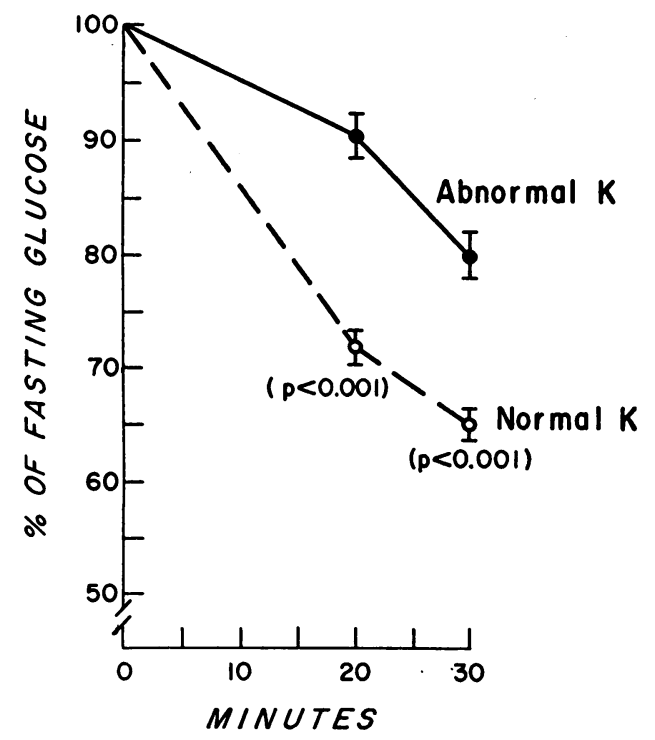

Fig. 1. CoMparison OF BLOOD GLUCOSE (MEAN \pm STANDARD ERROR OF THE MEAN) VALUES DURING IV TOLBUTAMIDE TEST BEFORE AND AFTER CORRECTION OF IV GLUCOSE TOLERANCE TEST (IVGTT) BY DIALYSIS IN UREMIC PATIENTS. "Normal" K (disappearance rate constant for glucose) = $\mathrm{K}>1.0$. $\mathrm{n}=11$ in each group.

ranged in any of the patients, and values ranged from 3.6 to $5.8 \mathrm{mEq}$ per $\mathrm{L}$ (mean $=4.7 \mathrm{mEq}$ per L). Of the two patients who were evaluated after only 1 week of dialysis (Patients 1 and 4), one had not maximally corrected his ivGTT after 3 dialyses (Patient 4 ), and the other demonstrated a lower $\mathrm{K}(0.8$ to 0.6$)$ after 5 dialyses.

Four of the patients showed a decrease in glucose tolerance in less than 8 days when dialysis was withheld or limited to 1 per week. Patient 5 demonstrated this decrease over a 2 -week period when the number of dialyses had been reduced from 4 to $1 \frac{1}{2}$ per week. Those patients whose glucose tolerance was corrected a second time $(\mathrm{Pa}-$ tients $1,2,3$, and 5 ) had done so by 14 days with a total of 4 to 12 dialyses. However, the ivGTT was repeated at the end of 1 week in three patients (Patients 1, 2, and 5) during this recorrection period and had not fully been repaired in any patient.

The glucagon test suggested adequate glycogen stores in the four patients in whom it was performed. In two patients, it was performed during the initial period when the ivGTT was abnormal
(Patients 3 and 4), and in one (Patient 2) during the redevelopment of carbohydrate intolerance. In one (Patient 1 ), it was done at a time when the ivGTT appeared to be normalizing.

The hydrocortisone ivGTT was done in four patients when dialysis was associated with a normal ivGTT and was normal in three. Patient 4, whose maternal grandmother suffered with diabetes mellitus, demonstrated a fall with hydrocortisone in the $\mathrm{K}$ from 1.8 to 0.7 .

Patient 3 developed mild serum hepatitis (documented by liver biopsy) shortly after the onset of testing. He had recently undergone bilateral nephrectomy in preparation for renal homotransplantation. He slowly recovered over a 10 -week period with return to normal of the serum glutamic oxaloacetic transaminase and then was continued with the protocol. He was the only anephric patient studied.

A high urea dialysate concentration was used in Patients 1 and 2. The dialyses with urea were instituted at a time when the ivGTT was normal, and there was no decrease in the $K$ value at the end of three and six dialyses over a 7 - and 8-day period, respectively.

The intravenous tolbutamide test followed the ivGTT. The 20- and 30-minute blood glucose values for individual patients (expressed as per cent of fasting blood glucose) are recorded in

INSULIN SENSITIVITY TEST

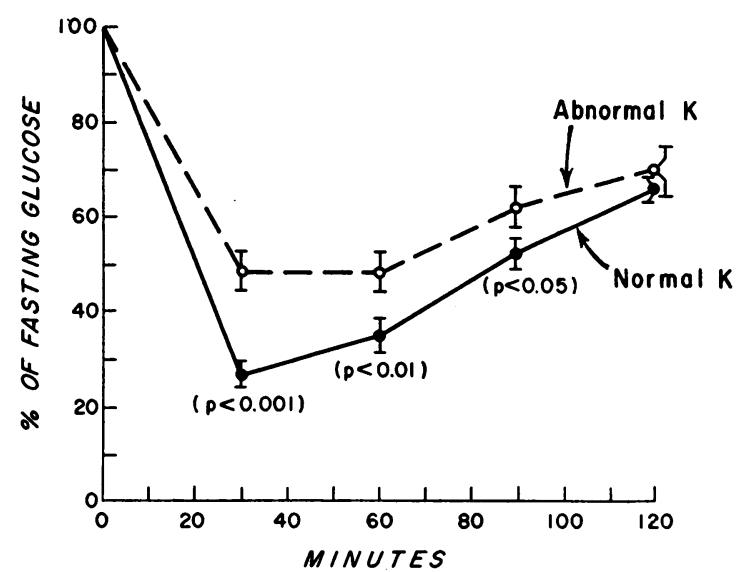

Fig. 2. Response of BLOOD GLUCOSE (MEAN \pm STANDARD ERROR OF THE MEAN) TO EXOGENOUS INSULIN ( $0.1 \mathrm{U}$ PER KG) BEFORE AND AFTER CORRECTION OF IVGTT BY DIALYSiS IN UREMIC PATIENTS. "Normal" $\mathrm{K}=\mathrm{K}>1.0$. $n=11$ in each group. 


\section{INSULIN RESPONSE TO I.V. G.T.T.}
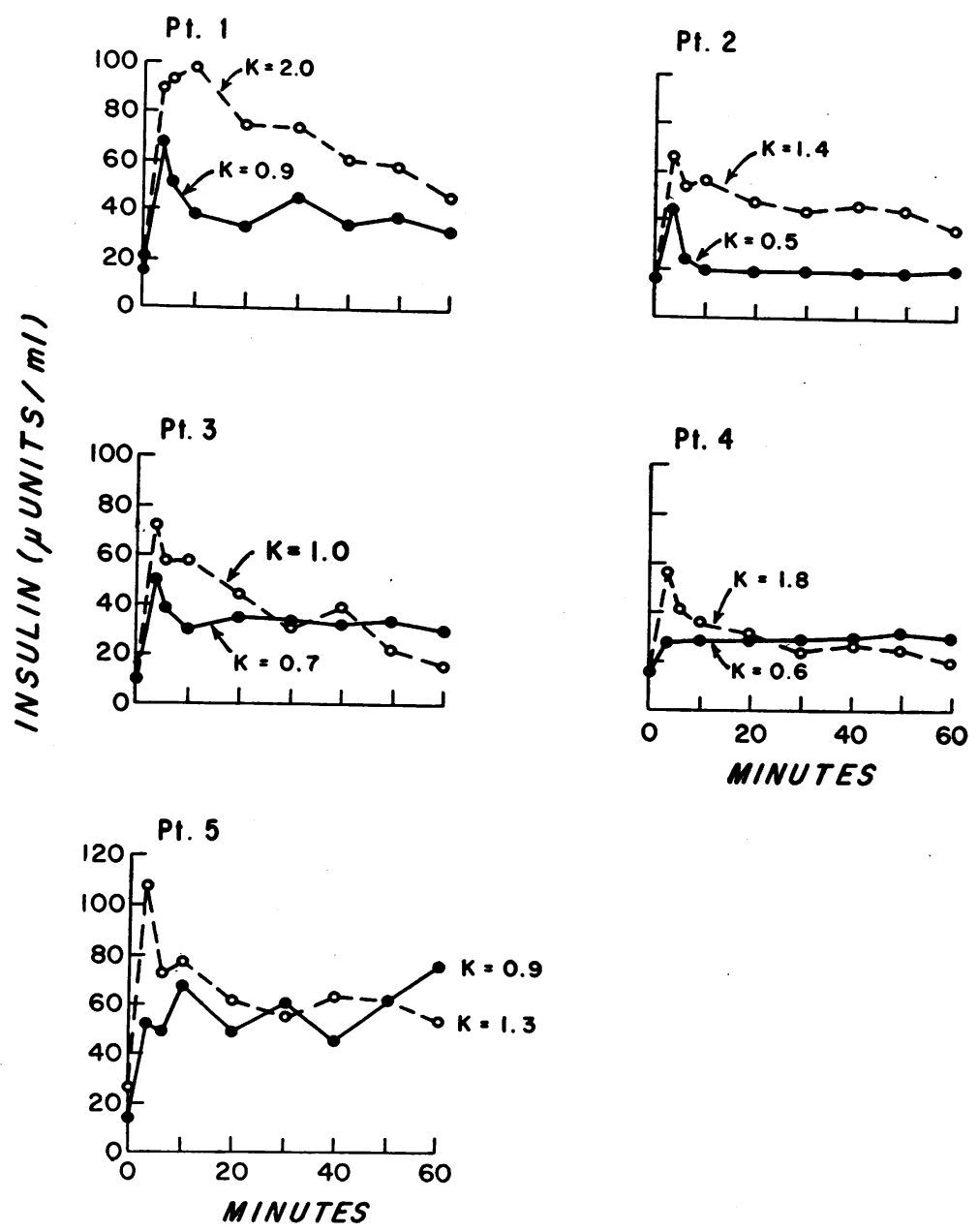

Fig. 3. Individual PATterns OF INSULIN RESPONSE to IVGTT BEFORE AND AFTER CORRECTION BY HEMODIALYSIS IN PATIENTS WITH CHRONIC RENAL FAILURE. The major difference in the response is noted during the first 10 minutes of insulin release.

Table II. Figure 1 shows the mean values \pm standard error of the mean comparing the tests performed at times when the ivGTT was normal and abnormal. A highly significant difference $(p<0.001)$ for the 20 - and 30 -minute samples was present.

The insulin sensitivity tests were performed during the periods when ivGTT was normal and abnormal. The lowest blood glucose achieved as a per cent of the fasting value is recorded in Table II with the mean values at $30,60,90$, and 120 minutes illustrated in Figure 2. There was a significant increase in insulin sensitivity after cor- rection of the ivGTT. The differences between the mean values at the $30-, 60$-, and 90 -minute samples are all significant $(p<0.05)$. In neither group had the glucose value returned to fasting levels at the end of 2 hours.

Fasting blood glucose was compared during normal and abnormal periods as judged by ivGTT, and no significant difference was found. This was true for fasting values obtained with all tests as well as for individual tests (data not shown).

Serum IRI responses to the ivGTT before and after correction of the $K$ value are shown in Figure 3. The abnormal test chosen for compari- 
TABLE III

Values for per cent ideal weight, $K$, age, and serum immunoreactive

\begin{tabular}{|c|c|c|c|c|c|c|}
\hline \multirow[b]{2}{*}{ Group } & \multirow[b]{2}{*}{$\mathbf{n}$} & \multirow[b]{2}{*}{ Ideal wt } & \multirow[b]{2}{*}{$\underset{(\mathrm{K})}{\operatorname{ivGTT}}$} & \multirow[b]{2}{*}{ Age } & \multicolumn{2}{|c|}{ Insulin } \\
\hline & & & & & $\underset{\min }{0}$ & $\underset{\min }{3}$ \\
\hline & & $\%$ & & years & & \\
\hline \multirow{7}{*}{$\begin{array}{l}\text { Uncorrected uremics } \\
\text { Corrected uremics } \\
\text { Difference: corrected minus } \\
\text { uncorrected } \\
\text { Normals (wt }=<95 \% \text { ideal wt) } \\
\text { Normals }(\mathrm{K}=1.2-2.0) \\
\text { Diabetics }(\mathrm{K}=<1.2) \\
\text { 7-day fast (normals) }\end{array}$} & 5 & $82 \pm 2.5^{*}$ & $0.73 \pm 0.09$ & $34 \pm 3.2$ & $13.8 \pm 1.0$ & $48.8 \pm 6.6$ \\
\hline & 5 & $81 \pm 2.4$ & $1.47 \pm 0.19$ & $34 \pm 3.2$ & $19.6 \pm 1.9$ & $78.0 \pm 9.1$ \\
\hline & 5 & & & & $5.8 \pm 1.9$ & $27.2 \pm 7.5$ \\
\hline & 15 & $90 \pm 1$ & $2.68 \pm 0.25$ & $27.7 \pm 0.8$ & $13.3 \pm 1.2$ & $72.4 \pm 6.5$ \\
\hline & 11 & $98 \pm 3$ & $1.72 \pm 0.05$ & $27.2 \pm 0.7$ & $14.3 \pm 1.8$ & $69.2 \pm 7.2$ \\
\hline & 9 & $109 \pm 10$ & $0.95 \pm 0.07$ & $50.3 \pm 3.6$ & $15.3 \pm 3.2$ & $30.3 \pm 2.8$ \\
\hline & 6 & $100 \pm 4.5$ & $0.625 \pm 0.02$ & $26.8 \pm 2.5$ & $8.3 \pm 1.0$ & $47.7 \pm 1.0$ \\
\hline
\end{tabular}

* Mean \pm standard error of the mean.

son in Patients 3 and 4 was that performed during the predialysis period (period 1 in Table II). Since we did not determine IRI during this period, in Patients 1,2 , and 5 , the test used was that done during the redevelopment of the abnormal $\mathrm{K}$ value ( $K$ less than 1.0) when dialysis was reduced. The insulin response to the normal ivGTT in Patients 1, 4, and 5 was the test with the maximal $\mathrm{K}$ value. In Patient 2 , the insulin levels of the ivGTT during period 4 (Table II), when the $\mathrm{K}$ was 2.0 , were not determined, and the ivGTT of period $7(\mathrm{~K}=1.4)$ was used. In Patient 3, because of the uncertain liver status and its effect on insulin, the ivGTT of period $5(\mathrm{~K}=1.0)$ instead of period $4(\mathrm{~K}=1.9)$ was used in comparing the insulin response. This was felt to be acceptable, as the $K$ value of 1.0 was slightly higher than the initial $\mathrm{K}$ of 0.7 . In all patients we compared the IRI during the ivGTT with the highest and lowest $\mathrm{K}$ value for which we had data.

The levels of IRI during the first 10 minutes of the precorrection ivGTT showed a blunted response. There was also a tendency for flattening of the later part of the curve.

Fasting insulin levels were slightly lower in all five patients during the abnormal phase. The total amount of insulin released was approximated by the area under the serum IRI curve extending to 60 minutes and was from 1.1 to 4 times greater in four of the five patients in the normal phase. Patient 4 demonstrated a 1 to 1.5 ratio of insulin when comparing normal to abnormal. However, during the first 10 minutes of the ivGTT, a greater amount of insulin was released in all cases when the test was normal and ranged from 1.6 to 3 times that seen during the abnormal periods.
Table III shows the characteristics and serum IRI levels (mean \pm standard error of the mean) during ivGTT in the uncorrected and corrected uremic patients. Also shown for comparison are various groups of normal controls. They were selected on the basis of either ideal weight or performance in order to closely approximate the uremic patients. Data are also given for six normal subjects who received ivGTT immediately after a 7-day total fast (17). The results obtained in nine diabetic subjects are also shown; however, it is to be noted that this group was significantly older and heavier than the uremic patients. Table IV compares the various groups studied.

In comparing the mean serum IRI levels between the corrected and uncorrected uremic patients, the levels in the corrected phase are significantly higher at 0,3 , and 6 minutes. When the data are analyzed as to differences in serum IRI values in each uremic patient before and after correction, significant differences are seen at the $0-, 3-, 6-, 10-, 20-$, and 40-minute intervals.

Comparison of the mean serum IRI levels during the abnormal ivGTT showed at least two significantly different levels (i.e., the uremic patients had lower values) when compared to normal controls all less than $95 \%$ of ideal weight, or normal controls with a low normal range of $\mathrm{K}$ rates (1.2 to 2.0). Comparison with the diabetic group (Figure 4) indicated that the uncorrected uremics had a significantly higher mean serum IRI level at the 3-minute interval although the diabetics were significantly older and heavier. The group with whom mean serum IRI values to ivGTT in the uncorrected uremics showed the least differences was a normal control group fasted 7 days 
TABLE III

insulin during ivGTT in uremic, normal control, and diabetic groups

\begin{tabular}{|c|c|c|c|c|c|c|}
\hline \multicolumn{7}{|c|}{ Insulin } \\
\hline$\underset{\min }{6}$ & $\underset{\mathrm{min}}{10}$ & $\underset{\min }{20}$ & $\begin{array}{l}30 \\
\min \end{array}$ & $\begin{array}{c}40 \\
\text { min }\end{array}$ & $\begin{array}{c}50 \\
\min \end{array}$ & $\begin{array}{c}60 \\
\min \end{array}$ \\
\hline \multicolumn{7}{|c|}{$\mu U / m l$} \\
\hline $\begin{array}{l}37.0 \pm 5.0 \\
64.0 \pm 9.0\end{array}$ & $\begin{array}{l}37.0 \pm 8.3 \\
65.0 \pm 10.6\end{array}$ & $\begin{array}{l}33.6 \pm 4.9 \\
52.4 \pm 7.4\end{array}$ & $\begin{array}{l}37.4 \pm 7.0 \\
46.4 \pm 8.9\end{array}$ & $\begin{array}{l}32.2 \pm 4.2 \\
48.2 \pm 6.6\end{array}$ & $\begin{array}{l}33.4 \pm 4.0 \\
42.6 \pm 8.3\end{array}$ & $\begin{array}{l}30.6 \pm 3.0 \\
35.0 \pm 7.2\end{array}$ \\
\hline $\begin{array}{l}27.2 \pm 6.2 \\
64.1 \pm 7.0 \\
58.1 \pm 5.9 \\
29.4 \pm 2.7 \\
42.7 \pm 6.1\end{array}$ & $\begin{array}{l}28.8 \pm 9.7 \\
51.4 \pm 5.4 \\
49.9 \pm 5.8 \\
30.8 \pm 4.6 \\
40.7 \pm 7.3\end{array}$ & $\begin{array}{l}18.8 \pm 6.9 \\
40.3 \pm 4.0 \\
47.2 \pm 6.7 \\
32.8 \pm 5.7 \\
29.8 \pm 5.9\end{array}$ & $\begin{array}{r}9.0 \pm 7.6 \\
33.7 \pm 3.2 \\
44.7 \pm 6.8 \\
31.1 \pm 6.4 \\
22.7 \pm 2.7\end{array}$ & $\begin{array}{l}16.2 \pm 5.9 \\
27.7 \pm 2.5 \\
43.1 \pm 6.4 \\
34.3 \pm 5.8 \\
21.3 \pm 2.1\end{array}$ & $\begin{array}{r}9.2 \pm 8.0 \\
23.2 \pm 1.7 \\
39.5 \pm 6.4 \\
35.5 \pm 6.3 \\
20.8 \pm 2.7\end{array}$ & $\begin{array}{r}4.4 \pm 6.8 \\
17.9 \pm 1.4 \\
34.4 \pm 6.7 \\
35.4 \pm 6.4 \\
21.5 \pm 2.4\end{array}$ \\
\hline
\end{tabular}

(shown in Figure 4). The starved patients had a significantly lower mean serum IRI level at the 60-minute point only.

When the uremics were corrected and exhibited normal $\mathrm{K}$ rates, they compared well with the normal group with $\mathrm{K}$ rates in the 1.2 to 2.0 range despite a higher mean per cent ideal weight of this normal group.

The corrected uremic patients had multiple significantly different mean serum IRI levels (higher values) compared to the diabetics, and the 7-day fasted normals and the diabetics and the fasted normal controls also showed multiple differences.

Mean values for FFA determined throughout the ivGTT performed during the uncorrected and corrected periods are shown in Table V. No significant differences were found between the two.

\section{Discussion}

From the results of this study, it appears that the glucose intolerance of chronic renal failure is related to the renal failure per se and is not a secondary feature of low calorie intake. This conclusion is based on calorie counting before and during the period of study and on the response to glucagon stimulation (18). In addition, it has long been recognized that patients with renal failure do not demonstrate fasting hypoglycemia as would be expected with starvation and, indeed, have been noted to manifest fasting hyperglycemia

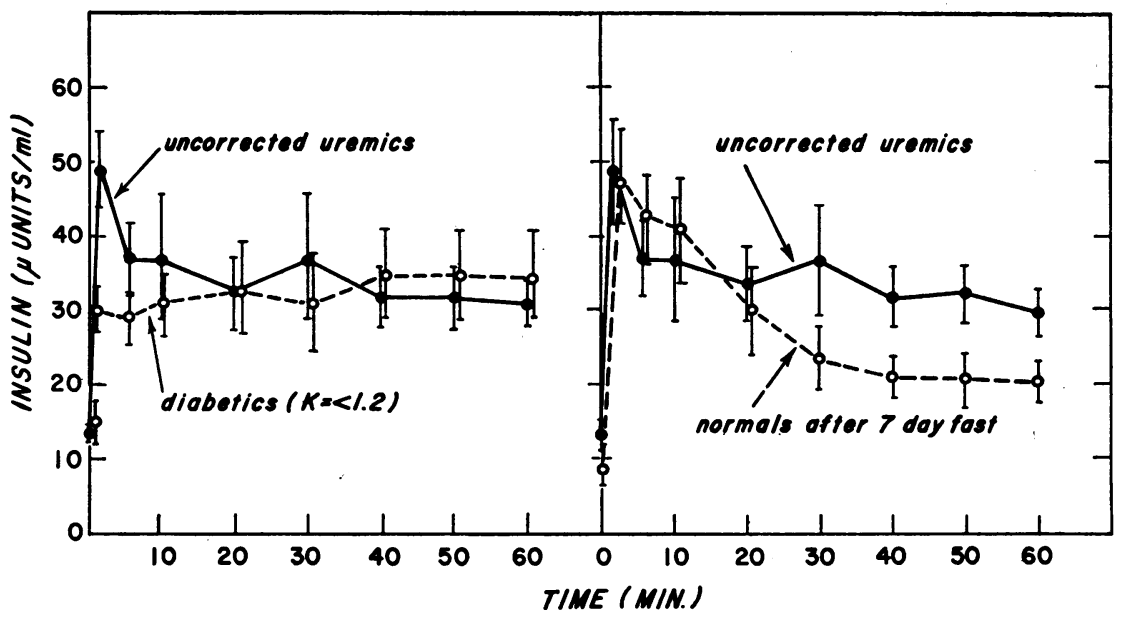

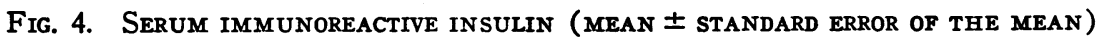
DURING IVGTT IN UNCORRECTED UREMICS AND DIABETICS AND UNCORRECTED UREMICS AND NORMAL CONTROLS AFTER A 7-DAY FAST. Insulin release during the first $10 \mathrm{~min}$ utes of the ivGTT is virtually identical in the graph on the right. 


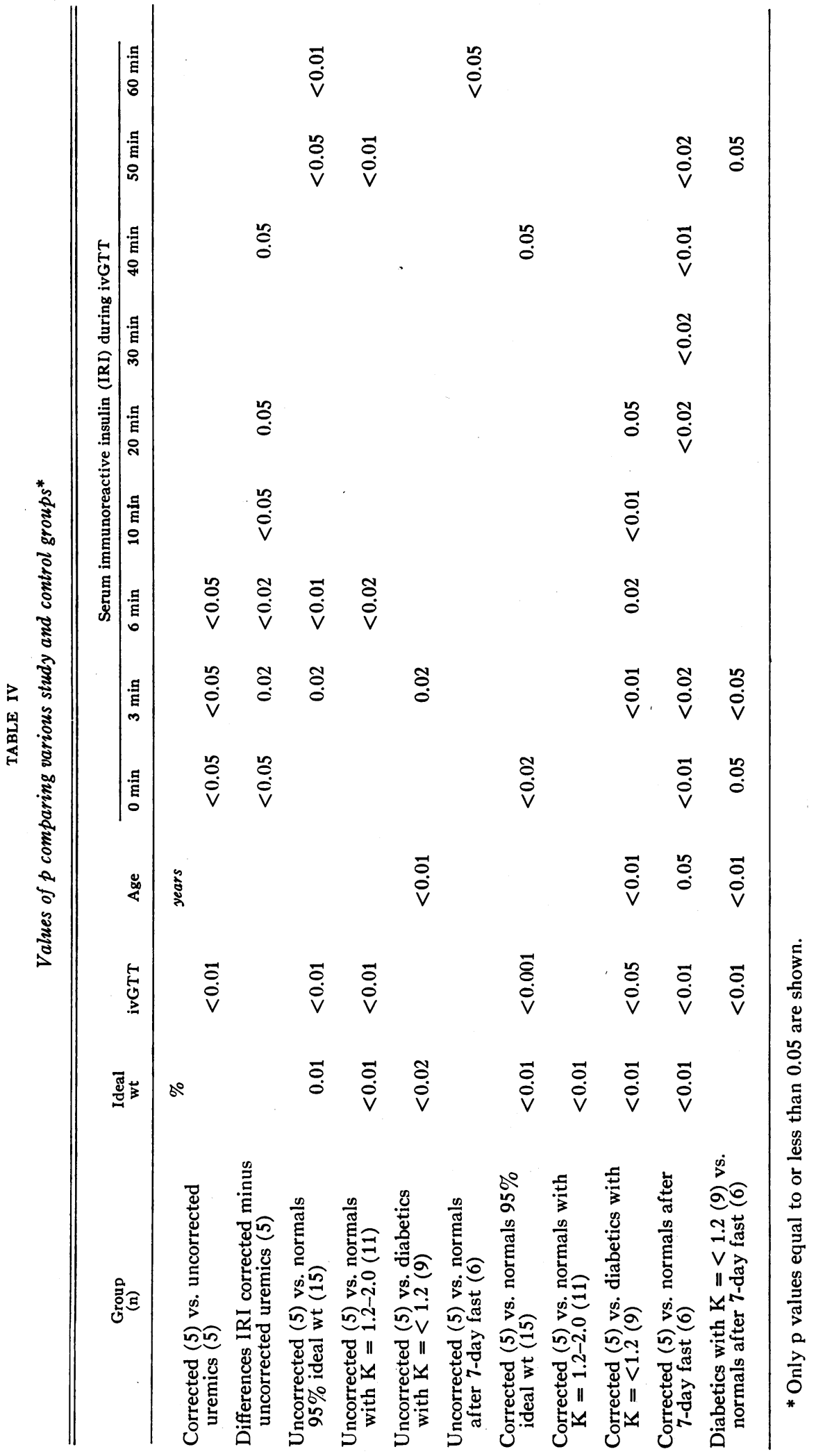


(19). Since the patients who were included in this study did not have significant nausea or vomiting, it was possible to accurately assess their intake and ensure that all had adequate total calories in addition to sufficient carbohydrate. For these patients with a relatively low level of physical activity, the diets ingested should have been adequate for their caloric needs (20).

These uremic patients required only an abnormal ivGTT while maintaining adequate diet, and chronic renal failure of a degree that necessitated dialysis, to be selected for this study. The first consecutive five patients encountered were selected because in each the ivGTT was abnormal and their caloric intake was acceptable. This suggests that the carbohydrate abnormality in chronic renal failure is common and may be present in the majority of severely uremic patients even while they maintain adequate food intake. This study also suggests that the abnormal glucose tolerance associated with chronic renal failure can not only be corrected but maintained with adequate hemodialysis. It has been shown previously that the glucose tolerance test will improve by dialysis in patients with acute renal failure (21), but it has not been conclusively demonstrated that it can be maintained normal in the patient with chronic renal disease undergoing long term dialysis.

Four other patients (Table VI) maintained with chronic hemodialysis and tested by ivGTT all had normal $\mathrm{K}$ values. This indicates that an abnormal ivGTT in a patient being treated with intermittent hemodialysis may be indicative of inadequate dialysis, or if seen during intensive dialysis that diabetes mellitus should be considered. The blood urea nitrogen and other chemical parameters are often misleading when judging the dialysis requirement, and another parameter (such

TABLE V

Levels of FFA determined during ivGTT

\begin{tabular}{cccccc}
\hline \hline & $0 \mathrm{~min}$ & $10 \mathrm{~min}$ & $20 \mathrm{~min}$ & $40 \mathrm{~min}$ & $60 \mathrm{~min}$ \\
\hline & & \multicolumn{5}{c}{$\mu E q / L$} \\
Uncorrected & 708 & 630 & 528 & 438 & 442 \\
uremics & $\pm 77 *$ & \pm 75 & \pm 79 & \pm 46 & \pm 46 \\
Corrected & 764 & 500 & 464 & 414 & 438 \\
uremics & \pm 97 & \pm 87 & \pm 76 & \pm 49 & \pm 77 \\
$t$ & 0.45 & 1.13 & 0.58 & 0.36 & 0.05 \\
$\mathrm{p}$ & $\mathrm{NS} \dagger$ & $\mathrm{NS}$ & $\mathrm{NS}$ & $\mathrm{NS}$ & $\mathrm{NS}$ \\
\hline
\end{tabular}

* Mean \pm standard error of the mean.

$\dagger \mathrm{NS}=$ not statistically significant, $\mathrm{p}>\mathbf{0 . 2}$.

\begin{tabular}{cccccccr}
\multicolumn{8}{c}{ TABLE vI } \\
ivGTT of patients being maintained with \\
biweekly hemodialysis \\
Patient
\end{tabular}

as the ivGTT) would be useful in assessing the adequacy of treatment.

Increasing the frequency of dialysis within the first 7 to 8 days did not shorten the time needed for correction of the ivGTT. Regardless of whether 3 or 5 dialyses per week were instituted, the ivGTT remained abnormal at the end of the first week. All patients demonstrated a normal $\mathrm{K}$ value when tested at about 2 weeks. This pattern was the case regardless of whether we were correcting the abnormality for the first time or recorrecting. In some of the patients who were corrected twice (Patients 1,2, and 3), the total number of hours of dialysis necessary for correction during a 2 -week period was less than that found to be without significant effect in a 1-week period on another occasion. However, glucose intolerance would appear within 8 days if dialysis was withheld. This suggests that dialysis might be removing a toxic substance (or substances) that inhibits glucose utilization. Furthermore, this material may not necessarily be poorly dialyzable as has been suggested (6). Indeed, the material itself may cross the dialysis membrane rapidly, but the affected tissue may require a recovery time for restoration of normal glucose metabolism. If this is the case, one would not expect to shorten the recovery time beyond roughly defined limits (perhaps through new protein synthesis) regardless of how intensive a course of hemodialysis is instituted.

Perkoff and colleagues (3) have suggested that urea may be playing an important role in glucose tolerance by interfering directly with carbohydrate metabolism. It is known that high concentrations of urea can affect enzyme systems in vitro (22, 23 ), and Perkoff and co-workers were able to show a decrease in the glucose tolerance of normal patients given a urea load. However, our 
data suggest that urea was not a major factor, as the two patients with normal $\mathrm{K}$ values (Patients 1 and 2) who underwent dialysis for a 7-day period against a urea dialysate concentration identical to that present when the ivGTT was abnormal did not develop an abnormal ivGTT. In these same patients, withholding dialysis for 7 days produced an abnormal ivGTT. This is strong evidence that urea alone cannot be incriminated.

It has been suggested by Westervelt and Schreiner that the intravenous tolbutamide test can be used to distinguish between diabetes mellitus and the carbohydrate intolerance of uremia (6). These investigators found that seven uremic patients with abnormal glucose tolerance had a normal blood sugar response 30 minutes after tolbutamide injection, and several of their patients also had adequate lowering of blood sugar at the 20-minute interval.

These results, coupled with a decreased sensitivity to exogenous insulin, led the authors to speculate that in uremia there may be an abnormal plasma insulinase system (formed in the liver) that inactivates insulin in its passage through the liver. This was felt to account for the impaired peripheral glucose utilization without altering hepatic glycogenesis. Our results with intravenous tolbutamide are in contrast to those of Schreiner. This test, in our hands, demonstrated a clear $(\mathrm{p}<$ 0.001 ) difference between the uremic and corrected (posthemodialysis) state and was clearly abnormal in all uncorrected patients and paralleled glucose tolerance.

The insulin sensitivity test improved after correction of the ivGTT and is in keeping with the mild insulin resistance of nondiabetic uremic patients reported previously $(3,5)$. On several occasions, patients with an abnormal ivGTT demonstrated a fall in the fasting blood sugar, after insulin, greater than 50\%. Although this has been accepted as a normal response (15), comparative values after correction of the ivGTT demonstrated an even greater insulin sensitivity.

The steroid-primed ivGTT, which will be abnormal in a great proportion of latent diabetics (16), was normal in three of the four patients tested. In the one patient with a family history of diabetes, the test was abnormal, and one might speculate as to whether this patient's carbohydrate abnormality was in part a manifestation of underlying diabetes mellitus. All other tests performed on this patient were similar to those found in the others. However, it is of considerable interest that the serum IRI response to ivGTT when corrected and uncorrected was the lowest in the series.

There exists other evidence that the type of carbohydrate derangement present with uremia is different from that seen in diabetes mellitus. Cohen (5) has shown that uremic patients, unlike diabetics, are unable to handle a galactose load. This present study can add additional differences. The incidence of the glucose intolerance of renal failure, as judged from this series, is much higher than one would expect on the basis of diabetes mellitus in random sampling. Furthermore, the pattern of serum IRI response found during ivGTT appears to be different from that seen in diabetes. With maturity-onset type diabetes, the insulin response to ivGTT seen at 3,6, and 10 minutes (as judged by mean values) is depressed below that seen in the uncorrected uremics. However, in this small series and between these crudely matched groups the difference is statistically significant only at 3 minutes $(p<0.05)$. The pattern of insulin release seen in the uremic patients, especially during the early part of the test, is similar to that of normal subjects who have been starved for 7 days.

The magnitude and pattern of the serum IRI response found in individual patients show moderate variations, and this was the basis for comparing the levels during normal and abnormal glucose tolerance in the same patient. The pattern of serum IRI during ivGTT in a normal subject, as detected with the double antibody assay method, appears to be very reproduceable on repeated testing (24). The change in response seen in all our patients is, therefore, significant. It shows a decrease in magnitude of peripheral serum insulin with uremia that is manifested principally during the first 10 minutes after ivGTT. This early response was shown to increase by 1.6 to 3 times when the ivGTT had been corrected by dialysis.

Cerletty and Engbring (25) have recently measured serum immunoreactive insulin release in azotemic patients during an oral glucose tolerance test. These investigators found elevated periph- 
eral insulin levels at $\frac{1}{2}, 1,2$, and 3 hours after the glucose load. It is difficult to compare results, as the insulin response to the oral and intravenous glucose tolerance tests are quite different (26). Insulin release is considerably greater after oral loading with glucose even with identical loads and probably reflects gastrointestinal and/or other factors triggered by alimentary glucose that influence pancreatic insulin secretion.

The exact role of FFA in diabetes mellitus or in glucose tolerance itself is unsettled. It has been suggested by Hales and Randle (27) that the defect in carbohydrate metabolism seen with diabetes may be secondary to an increase in FFA, which in turn, is indicative of an as yet undefined abnormality of lipid metabolism. There is further evidence demonstrated by Schalch and Kipnis (28) relating artificially elevated plasma levels of FFA to decreased glucose tolerance. In our study, however, there was no significant difference in fasting FFA between the uncorrected and corrected uremic patients, nor was there any difference in the FFA response to glucose loading. From our data, we would conclude that an elevated level of circulating FFA is not a critical factor in the carbohydrate abnormality of uremia.

Severe acidosis has been shown to affect glucose tolerance in dogs (29), and recent work suggests a close relationship between serum and total body potassium and glucose intolerance (30). A1though we did not measure blood $\mathrm{pH}$ or $\mathrm{PCO}_{2}$ in our patients, neither of these factors would appear to be decisively important in our study, as neither the $\mathrm{HCO}_{3}^{-}$[which in patients undergoing dialysis is a reflection of blood $\mathrm{pH}$ (31)] nor serum potassium was markedly deranged during any of the periods in this study (Table II).

The kidney is known to take an active part in carbohydrate metabolism (32) and may have a place in regulating blood glucose (33). However, it is difficult to assign to it a direct metabolic role in the present situation. The fact that we can correct the carbohydrate abnormality with dialysis, coupled with the demonstration that anephric man (Patient 3 ) responded in the same manner as the other patients, would argue against the carbohydrate intolerance stemming from a biochemical defect involving primarily renal tissue.

The explanation that seems best to fit the data is one implicating a decreased pancreatic insulin reserve or release, suggested by the measurements of serum IRI during ivGTT. As noted, the initial serum IRI response was very similar to the diminished response seen with starvation in normal subjects and associated with abnormal ivGTT. In addition, the clear abnormality in the intravenous tolbutamide test would also indicate an impaired insulin release after tolbutamide. These data, including the insensitivity to exogenous insulin, could be explained on the basis of a diminished insulin response to glucose and tolbutamide with a decreased peripheral sensitivity to insulin.

The recovery period suggested by the pattern of response to dialysis to be necessary for restoration of normal carbohydrate handling could represent the time necessary for affected enzyme systems to recover, perhaps through new protein synthesis. One might speculate that material with a relatively low molecular weight is indirectly responsible for the metabolic defect. The substance may accumulate to significant levels and affect enzyme systems over a relatively short time, but could be rapidly dialyzed. This is suggested by the rapidity with which the glucose abnormality recurs when dialysis is limited, correction of the defect with comparatively few total hours of dialysis, and the exclusion characteristics of the dialysis membrane. The cellophane employed has an effective pore size that excludes most molecules with a molecular weight greater than 4,000 (34), and this defines the maximal size of any such material.

\section{Summary}

In an attempt to better define the carbohydrate intolerance of uremia, we investigated five patients with abnormal glucose tolerance and chronic renal failure severe enough to require hemodialysis. After we were assured that calorie intake was adequate, the patients were studied with tests of carbohydrate tolerance. In addition, serum immunoreactive insulin (IRI) and free fatty acids were determined in response to intravenous glucose (ivGTT). The patients then underwent frequent hemodialysis, after which they were reevaluated. The frequency of dialysis was subsequently varied in order to determine its effect on glucose metabolism.

Our data indicate the following: 1) There is a defect in carbohydrate metabolism present in ure- 
mia that is not related to secondary factors, such as starvation or latent diabetes mellitus.

2) This abnormality does not appear to be related to urea per se.

3) The glucose intolerance can be corrected with frequent hemodialysis, but a minimal recovery period (approximately 2 weeks) is necessary.

4) The insulin insensitivity and abnormal response to intravenous tolbutamide are also corrected with dialysis.

5) The carbohydrate abnormality will reappear within 7 days if dialysis is withheld.

6) There is a decreased serum IRI response to ivGTT noted primarily within the first $10 \mathrm{~min}$ utes of testing. We compared mean values of IRI with various control groups and found that the uremic patients during the early phase of the test had depressed IRI similar to patients after a 7-day fast.

7) Circulating FFA levels were not significantly different during periods of normal and abnormal glucose tolerance.

We speculate that a small molecular weight substance (or substances) accumulates rapidly in uremia and affects carbohydrate metabolism (possibly by interfering with enzyme activity). This is manifest by a decreased serum insulin response to glucose loads and by a peripheral insensitivity to insulin.

\section{Acknowledgments}

We thank Dr. George F. Cahill, Jr., for his kind cooperation and helpful criticism in reviewing the manuscript. The technical assistance of Mrs. Marta Grinbergs is gratefully acknowledged, as well as the invaluable cooperation of Miss Barbara Fulton.

\section{References}

1. Myers, V. C., and J. A Killian. Studies on animal diastases. I. The increased diastase activity of the blood in diabetes and nephritis. J. biol. Chem. 1917, 29, 179.

2. Hamman, L., and I. I. Hirschman. Studies on blood sugar. I. Alimentary hyperglycemia and glycosuria as a test of sugar tolerance. Arch. intern. Med. 1917, 20, 761.

3. Perkoff, G. T., C. L. Thomas, J. D. Newton, J. C. Sellman, and F. H. Tyler. Mechanism of impaired glucose tolerance in uremia and experimental hyperazotemia. Diabetes 1958, 7, 375.

4. Luke, R. G., A. A. Dinwoodie, A. L. Linton, and A. C. Kennedy. Fructose and glucose tolerance in uremia. J. Lab. clin. Med. 1964, 64, 731.
5. Cohen, B. D. Abnormal carbohydrate metabolism in renal disease. Blood glucose unresponsiveness to hypoglycemia, epinephrine, and glucagon. Ann. intern. Med. 1962, 57, 204.

6. Westervelt, F. B., Jr., and G. E. Schreiner. The carbohydrate intolerance of uremic patients. Ann. intern. Med. 1962, 57, 266.

7. Hegstrom, R. M., J. S. Murray, J. P. Pendras, J. M. Burnell, and B. H. Scribner. Two years' experience with periodic hemodialysis in the treatment of chronic uremia. Trans. Amer. Soc. artif. intern. Organs 1963, 8, 266.

8. Lundbaek, $K$. Intravenous glucose tolerance as a tool in definition and diagnosis of diabetes mellitus. Brit. med. J. 1962, 1, 1507.

9. Somogyi, M. Notes on sugar determination. J. biol. Chem. 1952, 195, 19.

10. Nelson, N. A photometric adaptation of the Somogyi method for the determination of glucose. J. biol. Chem. 1944, 153, 375.

11. Morgan, C. R., and A. Lazarow. Immunoassay of insulin: two antibody system. Plasma insulin levels of normal, subdiabetic and diabetic rats. Diabetes 1963, 12, 115 .

12. Soeldner, J. S., and D. Slone. Critical variables in the radioimmunoassay of serum insulin using the double antibody technic. Diabetes 1965, 14, 771.

13. Dole, V. P., and H. Meinertz. Microdetermination of long-chain fatty acids in plasma and tissues. J. biol. Chem. 1960, 235, 2595.

14. Unger, R. H., and L. L. Madison. Comparison of response to intravenous sodium tolbutamide in mild diabetic and nondiabetic subjects. J. clin. Invest. 1958, 37, 627.

15. Fraser, R., F. Albright, and P. H. Smith. The value of the glucose tolerance test, the insulin tolerance test, and the glucose-insulin tolerance in the diagnosis of endocrinologic disorders of glucose metabolism. J. clin. Endocr. 1941, 1, 297.

16. Duncan, L. J. P. Cortisone induced impairment of glucose tolerance in the detection of the diabetic diathesis. Quart. J. exp. Physiol. 1956, 41, 453.

17. Cahill, G. F., Jr., M. G. Herrera, A. P. Morgan, J. S. Soeldner, J. Steinke, P. L. Levy, G. A. Reichard, Jr., and D. M. Kipnis. Hormone-fuel interrelationships during fasting. J. clin. Invest. 1966, 45, 1751.

18. Bondy, P. K., and L. R. Cardillo. The effect of glucagon on carbohydrate metabolism in normal human beings. J. clin. Invest. 1956, 35, 494.

19. Myers, V. C., and C. V. Bailey. The Lewis and Benedict method for the estimation of blood sugar, with some observations obtained in disease. J. biol. Chem. 1916, 24, 147.

20. Moore, F. D., and P. Ball. Metabolic Care of the Surgical Patient. Philadelphia, W. B. Saunders, 1959, p. 15.

21. Sagild, V. Glucose tolerance in acute ischemic renal failure. Acta med. scand. 1962, 172, 405. 
22. Harris, J. I. Effect of urea on trypsin and $\alpha$-chymotrypsin. Nature (Lond.) 1956, 177, 471.

23. Neurath, H., J. A. Rupley, and W. J. Dreyer. Structural changes in the activation of chymotrypsinogen and trypsinogen. Effect of urea on chymotrypsinogen and delta-chymotrypsin. Arch. Biochem. 1956, 65, 243.

24. Soeldner, J. S. Unpublished observations.

25. Cerletty, J. M., and N. H. Engbring. Azotemia and carbohydrate intolerance. Clin. Res. 1965, -13, 423.

26. Elrick, H., L. Stimmler, C. J. Hlad, Jr., and Y. Arai. Plasma insulin response to oral and intravenous glucose administration. J. clin. Endocr. 1964, 24, 1076.

27. Hales, C. N., and P. J. Randle. Effects of lowcarbohydrate diet and diabetes mellitus on plasma concentrations of glucose, non-esterified fatty acid, and insulin during oral glucose-tolerance tests. Lancet 1963, 1, 790.

28. Schalch, D. S., and D. M. Kipnis. Abnormalities in carbohydrate tolerance associated with elevated plasma nonesterified fatty acids. J. clin. Invest. 1965, 44, 2010.
29. Mackler, B., H. Lichtenstein, and G. M. Guest. Effects of ammonium chloride acidosis on glucose tolerance in dogs. Amer. J. Physiol. 1952, 168, 126.

30. Conn, J. W. Hypertension, the potassium ion and impaired carbohydrate tolerance. New Engl. J. Med. 1965, 273, 1135.

31. Hampers, C. L., P. B. Doak, N. Callaghan, H. R. Tyler, and J. P. Merrill. Cerebrospinal and electroencephalographic evaluation of hemodialysis. Arch. intern. Med. In press.

32. Krebs, H. A., and T. Yoshida. Renal gluconeogenesis. 2. The gluconeogenic capacity of the kidney cortex of various species. Biochem. J. 1963, 89, 398.

33. Okuma, M. Clinical pathophysiological investigation on the renal carbohydrate metabolism. Japanese Circulat. J. (En.) 1964, 28, 602.

34. Craig, L. Fractionation and characterization by dialysis in A Laboratory Manual of Analytic Methods of Protein Chemistry, P. A. Alexander and R. J. Block, Eds. New York, Pergamon, 1960, vol. 1, p. 103 . 